\title{
Development of Cu-based Oxygen Carriers for Chemical-Looping Combustion
}

\author{
Luis F. de Diego ${ }^{\text {a,* }}$, Francisco García-Labiano ${ }^{a}$, Juan Adánez ${ }^{a}$, Pilar Gayán ${ }^{\text {a }}$, Alberto \\ Abad $^{a}$, Beatriz M. Corbella ${ }^{b}$, Jose María Palacios ${ }^{b}$ \\ ${ }^{a}$ Instituto de Carboquímica (CSIC), Department of Energy and Environment, Miguel Luesma \\ Castán 4, 50015 Zaragoza, Spain \\ ${ }^{\mathrm{b}}$ Instituto de Catálisis y Petroleoquímica (CSIC), Campus UAM-Cantoblanco, 28049 Madrid, \\ Spain
}

\begin{abstract}
In a chemical-looping combustion (CLC) process, gas (natural gas, syngas, etc) is burnt in two reactors. In the first one, a metallic oxide that is used as oxygen source is reduced by the feeding gas to a lower oxidation state, being $\mathrm{CO}_{2}$ and steam the reaction products. In the second reactor, the reduced solid is regenerated with air to the fresh oxide, and the process can be repeated for many successive cycles. $\mathrm{CO}_{2}$ can be easily recovered from the outlet gas coming from the first reactor by simple steam condensation. Consequently, CLC is a clean process for the combustion of carbon containing fuels preventing the $\mathrm{CO}_{2}$ emissions to atmosphere. The main drawback of the overall process is that the carriers are subjected to strong chemical and thermal stresses in every cycle and the performance and mechanical strength can decay down to unacceptable levels after enough number of cycles in use.

In this paper the behaviour of $\mathrm{CuO}$ as an oxygen carrier for a CLC process has been analysed in a thermogravimetric analyser (TGA). The effects of carrier composition and preparation method used have been investigated to develop $\mathrm{Cu}$-based carriers exhibiting high
\end{abstract}


reduction and oxidation rates without substantial changes in the chemical, structural and mechanical properties for a high number of oxidation-reduction cycles. It has been observed that the carriers prepared by mechanical mixing or by coprecipitation showed an excellent chemical stability in multicycle tests in thermobalance, however, the mechanical properties of these carriers were highly degraded to unacceptable levels. On the other hand, the carriers prepared by impregnation exhibited excellent chemical stability without substantial decay of the mechanical strength in multicycle testing. These results suggest that copper based carriers prepared by impregnation are good candidates for chemical-looping combustion process.

Keywords: Chemical-looping combustion; $\mathrm{CO}_{2}$ capture; Copper oxide.

\section{Introduction}

It is generally accepted that a reduction of gas emissions promoting the greenhouse effect is a necessity in the industrial countries. Carbon dioxide coming from fossil fuel combustion is one of the most important greenhouse gases contributing to global warming. Until now, the main attention for decreasing $\mathrm{CO}_{2}$ emissions to atmosphere has been focused on the use of alternative energies and the increase of the efficiency in the conversion and use of energy. However, because it is not clear if it is possible to reach the desired low levels in $\mathrm{CO}_{2}$ emissions only by these ways, it is nowadays increasing the interest in using $\mathrm{CO}_{2}$ capture and sequestration from the combustion of fossil fuels as an alternative process [1]. For the capture and separation of $\mathrm{CO}_{2}$ from flue gases there are different techniques [2], however, the current processes of $\mathrm{CO}_{2}$ capture usually require a considerable energy consumption, leading to a reduction of the plant efficiency and increasing the cost of energy production [3].

\footnotetext{
* Corresponding author. Tel.: +34-976-733977; fax: +34-976-733318. E-mail: ldediego@carbon.icb.csic.es
} 
Chemical-looping combustion (CLC) was a process firstly proposed as a way to increase thermal efficiency in power generation [4-5], but later the possibility of using this combustion process for inherent $\mathrm{CO}_{2}$ separation without substantial energy losses was also recognised. This technology involves the use of a metal oxide as an oxygen carrier, which transfers oxygen from the air to the fuel avoiding the direct contact between fuel and air. The CLC system is made of two interconnected reactors, designated as air and fuel reactors. In the fuel reactor, the fuel gas is oxidised to $\mathrm{CO}_{2}$ and $\mathrm{H}_{2} \mathrm{O}$ by a metal oxide through the chemical reaction:

$$
\mathrm{CH}_{4}\left(\mathrm{CO}, \mathrm{H}_{2}\right)+\mathrm{MeO} \rightarrow \mathrm{CO}_{2}+\mathrm{H}_{2} \mathrm{O}\left(\mathrm{CO}_{2}, \mathrm{H}_{2} \mathrm{O}\right)+\mathrm{Me}
$$

where Me represents a metal or a reduced form of $\mathrm{MeO}$.

This metal or reduced oxide is further transferred into the air reactor in which it is oxidised with air:

$$
\mathrm{Me}+1 / 2 \mathrm{O}_{2} \rightarrow \mathrm{MeO}
$$

and the material regenerated is ready to start a new cycle.

The flue gas leaving the air reactor contains $\mathrm{N}_{2}$ and probably unreacted $\mathrm{O}_{2}$. The exit gas from the fuel reactor contains $\mathrm{CO}_{2}$ and $\mathrm{H}_{2} \mathrm{O}$, which are kept apart from the rest of the flue gas. After water condensation, almost pure $\mathrm{CO}_{2}$ can be obtained with little energy lost for component separation.

Different metal oxides have been proposed in the literature as potential candidates for CLC [4-6]: $\mathrm{CuO}, \mathrm{CdO}, \mathrm{NiO}, \mathrm{Mn}_{2} \mathrm{O}_{3}, \mathrm{Fe}_{2} \mathrm{O}_{3}$ and $\mathrm{CoO}$. In general, these metal oxides are prepared with an inert which acts as a porous binder enhancing the reactivity of the active phase and, probably, as an ionic conductor for oxygen [7-8]. Additionally, this inactive binder increases the mechanical strength and the attrition resistance of the oxygen carrier.

Depending upon the chemical nature of the metal oxide used, reaction 1 can be endothermic or exothermic, while reaction 2 is always exothermic. The total amount of heat 
evolved over the two reactors in CLC process is the same as in conventional combustion, however, thermodynamic considerations show that the exergy destructions in CLC are much lower than in conventional combustion, giving chance to increase the net power efficiency [45,9]. The only drawback of the overall CLC process is that the materials are subjected to strong chemical and thermal stresses in every cycle and the performance could be poor after enough number of cycles in use.

Mattisson and co-workers [10-12] have investigated the behaviour of natural and synthetic iron oxides in a CLC process using $\mathrm{CH}_{4}$ and air as feeding gases in fixed-bed and fluidisedbed reactors. They found for synthetic samples higher reaction rates and lower particle breakage as compared with the performance exhibited by natural samples. Recently, these authors [13] prepared $\mathrm{NiO}, \mathrm{CuO}, \mathrm{CoO}$, and $\mathrm{Mn}_{3} \mathrm{O}_{4}$ based carriers on alumina support by dry impregnation, and their reactivity was studied in a thermogravimetric analyser (TGA). They observed that the $\mathrm{Ni}$ or $\mathrm{Cu}$ containing materials showed high reactivity at all temperatures tested, however, Mn and Co containing carriers showed a rather poor reactivity. Ishida and co-workers [7,14-18] have investigated the effect of temperature, particle size, gas composition and pressure on the reduction and oxidation rates and on carbon deposition of $\mathrm{Fe}$, $\mathrm{Ni}$, and $\mathrm{Co}$ oxides in a TGA, using $\mathrm{H}_{2}, \mathrm{CO}$, or $\mathrm{CH}_{4}$ as fuels and air as oxidising gas. The effect of the inert used as a binder and its concentration was also analysed [7]. They concluded that the carbon deposition and the reaction rates and conversions, in addition to the operating conditions used (temperature, particle size, gas composition, total pressure, etc), depended strongly on the chemical nature of the solid materials [16-17].

Among the different metal oxides that have been proposed in the literature as potential candidates for $\mathrm{CLC}$ process, $\mathrm{CuO}$ and $\mathrm{Fe}_{2} \mathrm{O}_{3}$ are the less expensive having good oxygen capacities. 
The aim of this paper was the study of the behaviour of some potential $\mathrm{Cu}$-based oxygen carriers for a CLC process. The effects of the carrier composition and the preparation method used were investigated to develop oxygen carriers exhibiting high reduction and oxidation rates while maintaining their mechanical properties for a high number of successive oxidation-reduction cycles.

\section{Experimental}

\subsection{Preparation of oxygen carriers}

The prepared oxygen carriers are composed of $\mathrm{CuO}$ as active phase and an inert as a binder to increase the mechanical strength. The studied oxygen carriers will be designated with the chemical symbol referred to the active metal oxide $(\mathrm{Cu})$, followed by the weight concentration of $\mathrm{CuO}$, and a symbol referred to the binder used $(\mathrm{Al}=$ alumina, $\mathrm{Si}=$ silica, $\mathrm{Se}=$ sepiolite, $\mathrm{Ti}=$ titania, and $\mathrm{Zr}=\mathrm{zirconia})$. Finally, the preparation method used ( $\mathrm{M}=$ mechanical mixing, $\mathrm{C}=$ coprecipitation, and $\mathrm{I}=$ impregnation) is also included. For example, a sample designated as $\mathrm{Cu} 60 \mathrm{Se}-\mathrm{M}$ means a carrier composed of $60 \mathrm{wt} \%$ of $\mathrm{CuO}$ and $40 \mathrm{wt} \%$ of sepiolite and prepared by mechanical mixing.

Mechanical mixing. Oxygen carriers were prepared from commercial pure products as powders of particle size $<10 \mu \mathrm{m}$ including $\mathrm{CuO}$ as active phase and $\mathrm{Al}_{2} \mathrm{O}_{3}$, sepiolite, $\mathrm{SiO}_{2}$, $\mathrm{TiO}_{2}$, or $\mathrm{ZrO}_{2}$ as binders. Graphite was added during preparation, as a pore-forming additive, to create during calcination a suitable macroporosity that, presumably, may enhance the carrier reactivity in the two involved processes included in CLC. A powder mixture including the $\mathrm{CuO}$ and the binder in the desired concentration together with a $10 \mathrm{wt} \%$ of graphite was converted by water addition into a paste of suitable viscosity to be extruded in a syringe for obtaining cylindrical extrudates of about $2 \mathrm{~mm}$ diameter. These extrudates were softly dried at $80{ }^{\circ} \mathrm{C}$ overnight, cut at the desired length (about $1-2 \mathrm{~mm}$ ), and calcined at $950{ }^{\circ} \mathrm{C}$ for $6 \mathrm{~h}$ in a 
muffle oven. We have prepared these carriers in three different $\mathrm{CuO} /$ inert ratios $(40 / 60,60 / 40$, and $80 / 20)$.

Coprecipitation. A sample $\mathrm{Cu} 40 \mathrm{Si}-\mathrm{C}$ was also prepared by coprecipitation of $\mathrm{Cu}\left(\mathrm{NO}_{3}\right)_{2}$ and colloidal $\mathrm{SiO}_{2}$ from an aqueous solution followed by filtration, washing, and drying. The powder mixture obtained was further subjected to the same procedure as that applied to samples prepared by mechanical mixing.

Impregnation. In this case fresh extrudates of silica and titania as porous binders were prepared following the same method described for samples prepared by mechanical mixing, but calcining at $1100^{\circ} \mathrm{C}$. The extrudates were subsequently crushed, ground and sieved into particles of $200-400 \mu \mathrm{m}$ in size, in order to increase the efficiency of the subsequent impregnation with a saturated aqueous solution of $\mathrm{Cu}\left(\mathrm{NO}_{3}\right)_{2}$. The desired active phase loading was achieved by applying successive wet impregnations followed by calcination at $500{ }^{\circ} \mathrm{C}$ to decompose the impregnated copper nitrate into insoluble copper oxide.

\subsection{Characterization of oxygen carriers}

The crushing strength of the oxygen carriers as extrudates was determined by using the ASTM D-4179 method, which allows the measurement of the minimum normal force required to crush a cylindrical extrudate placed between two horizontal plates. The crushing strength was obtained dividing the applied force by the extrudate length. The final measure was obtained from the average of at least 15 different measurements undertaken on different extrudates randomly chosen.

The morphology and distribution of the elements of interest in the fresh oxygen carriers were studied in a scanning electron microscope (SEM) coupled to an $\mathrm{Si}(\mathrm{Li}) \mathrm{X}$-ray detector and a PGT SUN Sparcstation 5 for energy-dispersive X-ray (EDX) analysis. Identification and quantitative analysis of crystalline phases in the fresh samples were carried out by powder 
X-ray diffraction (XRD) in a diffractometer Seifert 3000 using Ni-filtered $\mathrm{Cu} \mathrm{K} \alpha$ radiation and a graphite monochromator.

\subsection{Reactivity tests}

Experimental set-up. Reactivity tests of the oxygen carriers were carried out in a thermogravimetric analyser (TGA), CI Electronics type, showed in Fig. 1. The TGA consisted of a quartz tube (24 mm i.d.) placed in an oven, which can be operated at temperatures up to $1100{ }^{\circ} \mathrm{C}$. The sample holder was a wire mesh platinum basket $(14 \mathrm{~mm}$ diameter and $8 \mathrm{~mm}$ height) to reduce mass transfer resistance around the solid sample. The temperature and sample weight were continuously recorded in a computer. $\mathrm{N}_{2}(9 \mathrm{~nL} / \mathrm{h})$ flowed through the microbalance head to keep the electronic parts free of the reactant gas. The flow rate of the reacting gas mixture $(25 \mathrm{~nL} / \mathrm{h})$ was controlled by electronic mass flow controllers and it was introduced at the upper part of the reaction tube. The gas was heated up to the desired temperature flowing down through the external annulus of the reactor before entering in contact with the sample located at the bottom of the reactor. The gas left the reactor through an internal quartz tube $(10 \mathrm{~mm}$ i.d.) after mixing with the gas coming from the head of the balance.

Procedure: For the reactivity experiments, the oxygen carrier (20-40 mg) was loaded in the platinum basket and heated to the set operating temperature in air atmosphere. After stabilisation, the experiment was started by exposing the oxygen carrier to alternating reducing and oxidising conditions. To avoid mixing of combustible gas and air, nitrogen was introduced for two minutes after each reducing and oxidising period. Some experiments without sample were initially carried out to detect the buoyancy effects due to the change of the reacting gases. 
The composition of the gas used was $\mathrm{CH}_{4}, \mathrm{H}_{2}$, or $\mathrm{CO}+\mathrm{H}_{2}$ for reduction and pure air for oxidation. The reducing gas was saturated in water by bubbling through a water containing saturator at the selected temperature to reach the desired water concentration (30 wt $\%)$. This $\mathrm{H}_{2} \mathrm{O}$ avoids or minimises the possible carbon deposition during the reduction reaction [13] and normally acts as an inert gas for the carrier reduction. The experiments were carried out at $800{ }^{\circ} \mathrm{C}$ because at higher operating temperatures $\mathrm{CuO}$, although stable in air, decomposes in $\mathrm{N}_{2}$ atmosphere into $\mathrm{Cu}_{2} \mathrm{O}$ with the subsequent loss of oxygen transport capacity of the carrier.

\section{Results and discussion}

At least five cycles of reduction and oxidation were carried out with each carrier. It was detected that the carriers normally stabilised after the first cycle, for which the reduction reaction rate was usually slower than the others. This feature was maybe due to the different changes produced in the structure of the fresh oxygen carriers during their first reduction reaction as compared with the different formation of the metal oxide during regeneration in successive cycles. In this work, the oxygen carrier reactivity corresponding to the cycle 5 was used for comparison purposes.

Data in reduction-oxidation TGA tests is directly obtained as a sample weight evolution as a function of the time. These weight data can be transformed into conversion data by using the following equations:

$$
\begin{aligned}
& \text { For reduction: } \quad X=\frac{m_{o x}-m}{m_{o x}-m_{r e d}} \\
& \text { For oxidation: } \quad X=1-\frac{m_{o x}-m}{m_{o x}-m_{r e d}}
\end{aligned}
$$

where $\mathrm{m}$ is the actual mass of sample, $\mathrm{m}_{\mathrm{ox}}$ is the mass of the sample fully oxidized and $\mathrm{m}_{\mathrm{red}}$ the mass of the sample in the reduced form. Reactions 5 and 6 show the reactants and products involved in the reactions of the Cu-based oxygen carriers using $\mathrm{CH}_{4}$ as reducing gas. 


$$
\begin{aligned}
& \mathrm{CH}_{4}+4 \mathrm{CuO} \rightarrow \mathrm{CO}_{2}+2 \mathrm{H}_{2} \mathrm{O}+4 \mathrm{Cu} \\
& 4 \mathrm{Cu}+2 \mathrm{O}_{2} \rightarrow 4 \mathrm{CuO}
\end{aligned}
$$

\subsection{Effect of the binder}

Fig. 2 shows the reactivity of pure $\mathrm{CuO}$ extrudates (without inert) as a function of the number of successive reduction-oxidation cycles in a typical multicycle test in TGA. In this case, the conversion $X^{*}$ plotted against the reaction time was defined as $X^{*}=\left(m-m_{r e d}\right) /\left(m_{o x}-\right.$ $\mathrm{m}_{\text {red }}$. As can be seen, for the reduction of $\mathrm{CuO}$ the result indicates that the particles reached complete conversion, however, the behaviour observed during the oxidation was different. The oxidation reaction rate of pure $\mathrm{CuO}$ decreased quickly with increasing the number of cycles and after three cycles of reaction the reactivity of the extrudates was extremely low, reaching conversions of only $10 \%$ in more than $20 \mathrm{~min}$. Similar results were found by Ishida and Jin [8] working with pure NiO. These researchers observed that the addition of a binder increased the oxidation rate and concluded that the binder plays dual roles: the role as an oxygen-permeable material and the role as a material to enhance the mechanical strength of the particle for cyclic use and against abrasion. As a drawback, it is worth noting that an increase in the amount of binder also yields a decrease in the oxygen transport capacity of the carrier.

Fig. 3 shows the reactivity data, obtained in TGA during the reduction and the oxidation reactions, for some of the oxygen carriers prepared by mechanical mixing using different binders and $\mathrm{CuO}$ concentrations as active phase. As can be seen in the figures, the reactivity of all carriers prepared using binders was very much higher than the reactivity of pure $\mathrm{CuO}$ particles. It may be concluded that the reduction and oxidation rates of the oxygen carriers prepared by mechanical mixing were highly dependent on the degree of conversion, and the 
binder type but, in general terms, all $\mathrm{Cu}$-based carriers studied exhibited high reactivities in reduction and oxidation. The reaction times for complete conversion in the reduction process were lower than 1 minute for all carriers and the oxidation conversion obtained at 1 minute of reaction time varied from 70 to $100 \%$. In most of the carriers the final oxidation rate was slower, probably by diffusional effects.

The identification of crystalline phases and their concentrations in some of the prepared carriers have been determined by powder XRD as shown in Table 1. Silica and alumina used as binders are microcrystalline giving diffuse X-ray patterns in opposition to zirconia and rutile that present very intense reflections allowing easy identification. Additionally, the active phase, $\mathrm{CuO}$, also presents a well-defined pattern. In sample $\mathrm{Cu} 40 \mathrm{Al}-\mathrm{M}$ the presence of a spinel-structure $\mathrm{CuAl}_{2} \mathrm{O}_{4}$ was clearly evidenced indicating that in this sample there was interaction between the active phase and binder through the formation of this mixed oxide. This effect could strongly alter the carrier behaviour on reduction, however, the corresponding plot in Fig. 3 shows complete conversion in reduction indicating that this spinel phase is also reducible by the feeding gas.

In addition to the studied reactivity, the mechanical strength of the carriers is another important parameter to be accounted as a criterion for material selection. Table 2 shows the crushing strength of all fresh extrudates prepared by mechanical mixing. The crushing strength mainly depended on the type of binder used and the carriers only showed appreciable crushing strength when using $\mathrm{SiO}_{2}$ and $\mathrm{TiO}_{2}$ as binders. These results in the case of $\mathrm{TiO}_{2}$ could be associated with some structural changes occurring for this binder during calcination at $950{ }^{\circ} \mathrm{C}$. X-ray diffraction patterns (Table 1) revealed that $\mathrm{TiO}_{2}$, present as anatase in the raw titanium oxide, was converted into rutile during calcination at high temperature. However, it is not so apparent when $\mathrm{SiO}_{2}$ was used as binder. Using these binders the crushing strength increased with the $\mathrm{CuO}$ content indicating that the $\mathrm{CuO}$ as active phase also 
plays an important role in the mechanical properties exhibited by the fresh extrudates. In general, a higher sintering temperature produces an increase in the crushing strength of the oxygen carriers, however, for the $\mathrm{Cu}$-based oxygen carriers the sintering temperature is limited by the decomposition or melting of the particles.

Based on the reactivity tests in thermobalance and crushing strength measurements it may be concluded that $\mathrm{CuO}$ based oxygen carriers prepared by mechanical mixing using $\mathrm{SiO}_{2}$ or $\mathrm{TiO}_{2}$ as binders are the most promising studied carriers to be used in CLC.

\subsection{Effect of the gas composition}

The effect of the gas composition on reactivity of sample Cu40Si-M is shown in Fig. 4. Two possible feeding gases to be used in a CLC process, $\mathrm{CH}_{4}$ as the main component of the natural gas and a mixture of $\mathrm{CO}$ and $\mathrm{H}_{2}$ simulating the coal gas composition from gasification, were analysed. In addition, $\mathrm{H}_{2}$ was also used as a reference. In reduction, complete conversion of the carrier was reached rapidly with all gases studied, however, the reaction rate depended upon the gas composition being lower for $\mathrm{CH}_{4}$ than for $\mathrm{H}_{2}$ or $\mathrm{H}_{2}+\mathrm{CO}$. The gas composition of the gas used in reduction, however, did not affect the rate of oxidation apparently in the subsequent process to complete the cycle.

\subsection{Effect of the preparation method}

The preparation method used may affect the degree of dispersion of the active phase $(\mathrm{CuO})$ in the oxygen carrier. To study this effect, a sample $\mathrm{Cu} 40 \mathrm{Si}-\mathrm{C}$ has been prepared by coprecipitation with identical composition of sample Cu40Si-M prepared by mechanical mixing. SEM-EDX line profiles of $\mathrm{Cu} \mathrm{K} \alpha$ and $\mathrm{Si} \mathrm{K} \alpha$ taken from the two samples revealed that $\mathrm{Si}$ and $\mathrm{Cu}$ were not chemically associated. XRD analysis confirmed the presence of $\mathrm{CuO}$ and $\mathrm{SiO}_{2}$. Additionally, the degree of dispersion of the $\mathrm{Cu}$ containing phase, $\mathrm{CuO}$, in sample 
Cu40Si-C was slightly higher than in sample Cu40Si-M. This different degree of dispersion of the active phase may affect both the chemical reactivity and the mechanical strength of the carriers.

Fig. 5 shows the reactivity data of both samples. During reduction the reactivity of the sample prepared by coprecipitation was slightly lower than the prepared by mechanical mixing, however, during the oxidation the reactivity was almost identical for both samples. Additionally, the mechanical strength of samples prepared by the two different methods (see Table 2) was not so much different and, consequently, both samples were selected to carry out further studies in multicycle tests in TGA.

The oxygen carriers exhibiting acceptable crushing strengths and high conversions and reactivities were further selected for 100-cycles testing in successive oxidation-reduction tests in TGA. In every cycle the carrier undergoes important chemical and structural changes at high operating temperature and, consequently, important changes in the performance of the carriers with the number of cycles are expected. Fig. 6 shows the reactivity of the sample $\mathrm{Cu} 40 \mathrm{Si}-\mathrm{M}$ in several selected cycles for reduction and oxidation. The curves are almost coincident revealing that the carrier reactivity was not affected substantially by the number of cycles in use. Similar results were observed with other carriers prepared by mechanical mixing and coprecipitation.

Fig. 7 shows the appearance at low magnification of samples Cu40Si-M and Cu40Ti-M fresh and after 100 and 20 cycles, respectively. As can be observed, the original cylindrical shape of the fresh extrudates was completely converted in an amorphous powder pile after reaction indicating that the mechanical strength of the carrier was severely affected. This effect was especially important using titania as binder. With this binder the mechanical strength of the fresh sample was high but, unfortunately, it decreased after few cycles in use. Additional information on the microscopic appearance of fresh and after-use carriers at higher 
magnification was obtained from SEM pictures shown in Fig. 8 taken from cross sections of samples Cu40Si-M and Cu40Si-C. As can be seen, the surface of the fresh extrudates appears granular and compact while the surface of the reacted particles contains large holes and cracks probably formed by thermal stress.

From these multicycle tests it can be concluded that $\mathrm{Cu}$-based oxygen carriers prepared by mechanical mixing or coprecipitation exhibit high reactivity and excellent chemical stability but poor mechanical strength. Consequently, the method of preparation must be improved to decrease the unacceptable rapid degradation of the mechanical properties of carriers as the number of cycles increases.

The effects of the accumulative chemical and thermal stresses in every cycle could be minimised if $\mathrm{CuO}$ as active phase is retained within the porous texture of an inert support. In this case, the inert support could be calcined at higher temperature to increase substantially its mechanical strength. Thermal sintering is not detrimental because the active phase $\mathrm{CuO}$ has not been incorporated yet and, additionally, the presence of macropores in the support could be assured. On the other hand, the reactivity of the active phase could be kept high in every cycle since the porous and rigid support would allow gas diffusion without rate limitations.

In this work, samples of titania and silica impregnated with $\mathrm{CuO}$ were prepared following the conventional method commented above. Fig. 9 shows the reactivity in 100 -cycles tests in TGA of samples Cu30Ti-I and Cu20Si-I. As can be observed in this figure, these carriers showed good chemical stabilities and high reactivities, similar to or even higher than those prepared by mechanical mixing or coprecipitation and calcined at lower temperature. Fig. 10 shows SEM micrographs of surfaces of the fresh and after-use Cu20Si-I and Cu30Ti-I carriers. The presence of holes or cracks clearly are not evidenced in after-use samples and crush strength measurements revealed that the mechanical properties of the fresh carriers were preserved after reaction in multicycle tests. These results suggest that carriers prepared by wet 
impregnation on rigid and porous supports are potential candidates for chemical-looping combustion. However, more experimental work is needed to analyse the behaviour of these carriers with respect to agglomeration during fluidised bed cyclic reactions.

\section{Conclusions}

The possibility of using $\mathrm{CuO}$ as an oxygen carrier for a CLC process was analysed in a thermogravimetric analyser (TGA). It was found that the oxidation rate of pure $\mathrm{CuO}$ extrudates decreased quickly with increasing the number of cycles and after three cycles the reaction rate becomes extremely low. The oxidation rate and maximum conversion for all studied carriers were dramatically increased by the addition of a binder.

The effects of carrier composition and preparation method were investigated in order to develop oxygen carriers exhibiting high reduction and oxidation rates but maintaining the mechanical properties for a high number of oxidation-reduction cycles. It was observed that all carriers prepared by mechanical mixing or coprecipitation exhibited excellent chemical stabilities, high reactivities, and complete conversions during the cyclic process, independently on the type of binder and on the $\mathrm{CuO}$ concentration. However, these carriers underwent unacceptable degradation of the mechanical properties in multicycle tests in thermobalance.

To reduce the effect of chemical and thermal stresses, $\mathrm{CuO}$ based carriers were prepared by wet impregnation using titania and silica as supports. These new carriers exhibited high reactivities and complete conversions in multicycle tests in TGA. In addition, they maintained the chemical and mechanical properties of the fresh carriers, suggesting that impregnated carriers are good candidates for chemical-looping combustion. 


\section{Acknowledgements}

This research was carried out with financial support from the Spanish Ministry of Science and Technology (Project PPQ-2001-2111) and the European Coal and Steel Community (Project 7220-PR125). 


\section{References}

[1] Herzog H, Eliasson B, Kaarstad O. Capturing greenhouse gases. Scientific American 2000; 282(2): 72-79.

[2] Smith IM. $\mathrm{CO}_{2}$ reduction - prospects for coal. IEA Coal Research 1999.

[3] Riemer P. Greenhouse gas mitigation technologies, an overview of the $\mathrm{CO}_{2}$ capture, storage and future activities of the IEA greenhouse gas R\&D programme. Energy Conversion and Management 1996; 37:655-70.

[4] Richter HJ, Knoche KF. Reversibility of Combustion Processes. ACS Symposium Series $1983 ; 235: 71-85$.

[5] Ishida M, Zheng D, Akehata T. Energy 1987; 12:147-54.

[6] Mattisson T, Lyngfelt A. Capture of $\mathrm{CO}_{2}$ using chemical-looping combustion. In First Biennial Meeting of the Scandinavian-Nordic Section of Combustion Institute, Göteborg, Sweden, 2001; p.163-68

[7] Ishida M, Jin H. A novel combustor based on chemical-looping reactions and its reaction kinetics. J of Chem Engng of Jpn 1994; 27:296-301.

[8] Ishida M, Jin H. A novel chemical-looping combustor without NOx formation. Ind Engng Chem Res 1996; 35:2469-72.

[9] Anheden M, Svedberg G. Exergy analysis of chemical-looping combustion systems. Energy Conversion and Management 1998; 39:1967-80.

[10] Mattison T, Lyngfelt A, Cho P. The use of iron oxide as an oxygen carrier in chemicallooping combustion of methane with inherent separation of $\mathrm{CO}_{2}$. Fuel 2001; 80:1953-62.

[11] Cho P, Mattison T, Lyngfelt A. Reactivity of iron oxide with methane in a laboratory fluidised bed - Application of chemical-looping combustion. In 7th Int. Conf. of Circulating Fluidised Bed Combustion. Niagara Falls, Ontario 2002, p. 599-602. 
[12] Mattison T, Lyngfelt A, Cho P. Possibility of using iron oxide as an oxygen carrier for combustion of methane with removal of $\mathrm{CO}_{2}-$ Application of chemical-looping combustion. In Fifth International Conference on Greenhouse Gas Control Technologies. Cairns:CSIRO, 2001. p. 205-10.

[13] Mattison T, Järdnäs A, Lyngfelt A. Reactivity of some metal oxides supported on alumina with alternating methane and oxygen - Application for chemical-looping combustion. Energy Fuels 2003, 17:643-51.

[14] Ishida M, Jin H, Okamoto T. A fundamental study of a new kind of medium material for chemical-looping combustion. Energy Fuels 1996; 10:958-63.

[15] Ishida M, Jin H, Okamoto T. Kinetic behavior of solid particle in chemical-looping combustion: Suppressing carbon deposition in reduction. Energy Fuels 1998; 12:223-29.

[16] Jin H, Okamoto T, Ishida M. Development of a novel chemical-looping combustion: Synthesis of a looping material with a double metal oxide of CoO-NiO. Energy Fuels $1998 ; 12: 1272-77$.

[17] Jin H, Okamoto T, Ishida M. Development of a novel chemical-looping combustion: Synthesis of a solid looping material of $\mathrm{NiO} / \mathrm{NiAl}_{2} \mathrm{O}_{4}$. Ind Engng Chem Res 1999; $38: 126-32$.

[18] Jin H, Ishida M. Reactivity study on natural-gas-fueled chemical-looping combustion by a fixed-bed reactor. Ind Engng Chem Res 2002; 41: 4004-07. 
Table 1. Crystalline phases and concentrations ( $\mathrm{wt} \%)$ in some of the studied carriers as determined by powder XRD.

\begin{tabular}{ll}
\hline Sample & Composition \\
\hline $\mathrm{Cu} 40 \mathrm{Al}-\mathrm{M}$ & $\mathrm{CuO}=26 \%, \mathrm{CuAl}_{2} \mathrm{O}_{4}=74 \%$, amorphous $\mathrm{Al}_{2} \mathrm{O}_{3}$ \\
$\mathrm{Cu} 40 \mathrm{Se}-\mathrm{M}$ & $\mathrm{CuO}=100 \%$, amorphous sepiolite \\
$\mathrm{Cu} 40$ Si-M & $\mathrm{CuO}=100 \%$, amorphous silica \\
$\mathrm{Cu} 40 \mathrm{Ti}-\mathrm{M}$ & $\mathrm{CuO}=40 \%$, rutile $=60 \%$ \\
$\mathrm{Cu} 40 \mathrm{Zr}-\mathrm{M}$ & $\mathrm{CuO}=41 \%, \mathrm{ZrO}_{2}=59 \%$ \\
\hline
\end{tabular}


Table 2. Crushing strength $(\mathrm{N} / \mathrm{mm})$ of the extrudates prepared by different methods and using different binders.

\begin{tabular}{ccccccc}
\hline $\begin{array}{c}\text { Preparation } \\
\text { method }\end{array}$ & $\mathrm{CuO}(\mathrm{wt} \%)$ & \multicolumn{5}{c}{ Binder } \\
\cline { 2 - 7 } & 80 & 3 & 4 & 22 & 66 & 6 \\
\hline $\mathrm{M}$ & 60 & 0 & 0 & 20 & 59 & 2 \\
$\mathrm{M}$ & 40 & 0 & 0 & 17 & 43 & 1 \\
$\mathrm{M}$ & 40 & - & - & 14 & - & - \\
$\mathrm{C}$ & 20 & - & - & 27 & - & - \\
$\mathrm{I}$ & 30 & - & - & - & 60 & - \\
$\mathrm{I}$ & & & & & & \\
\hline
\end{tabular}




\section{Captions of the figures}

Figure 1. Schematic drawing of the thermogravimetric analyzer.

Figure 2. Reactivity of pure $\mathrm{CuO}$ extrudates as a function of the number of reductionoxidation cycles, using $\mathrm{CH}_{4}$ as fuel.

Figure 3. Effect of the type of binder and $\mathrm{CuO}$ content on the reactivity of $\mathrm{Cu}$-based oxygen carriers prepared by mechanical mixing, using $\mathrm{CH}_{4}$ as fuel.

Figure 4. Effect of gas composition on the reactivity of $\mathrm{Cu}$-based oxygen carriers.

Figure 5. Comparison of the reactivity of the samples $\mathrm{Cu} 40 \mathrm{Si}-\mathrm{M}$ and $\mathrm{Cu} 40 \mathrm{Si}-\mathrm{C}$, using $\mathrm{CH}_{4}$ as fuel.

Figure 6. Effect of number of reduction-oxidation cycles on reactivity of sample Cu40Si-M, using $\mathrm{CH}_{4}$ as fuel.

Figure 7. Photographs of fresh and after reaction carrier particles prepared by mechanical mixing.

Figure 8. SEM micrographs of fresh and after 100 cycles tests in TGA of samples Cu80Si-M and $\mathrm{Cu} 40 \mathrm{Si}-\mathrm{C}$.

Figure 9. Effect of number of reduction-oxidation cycles on reactivity of samples prepared by impregnation, using $\mathrm{CH}_{4}$ as fuel.

Figure 10. SEM micrographs of fresh and after 100 cycles tests in TGA of samples Cu20Si-I and $\mathrm{Cu} 30 \mathrm{Ti}-\mathrm{I}$ prepared by impregnation. 
Development of Cu-based Oxygen Carriers for Chemical-Looping Combustion. Luis F. de Diego et al.

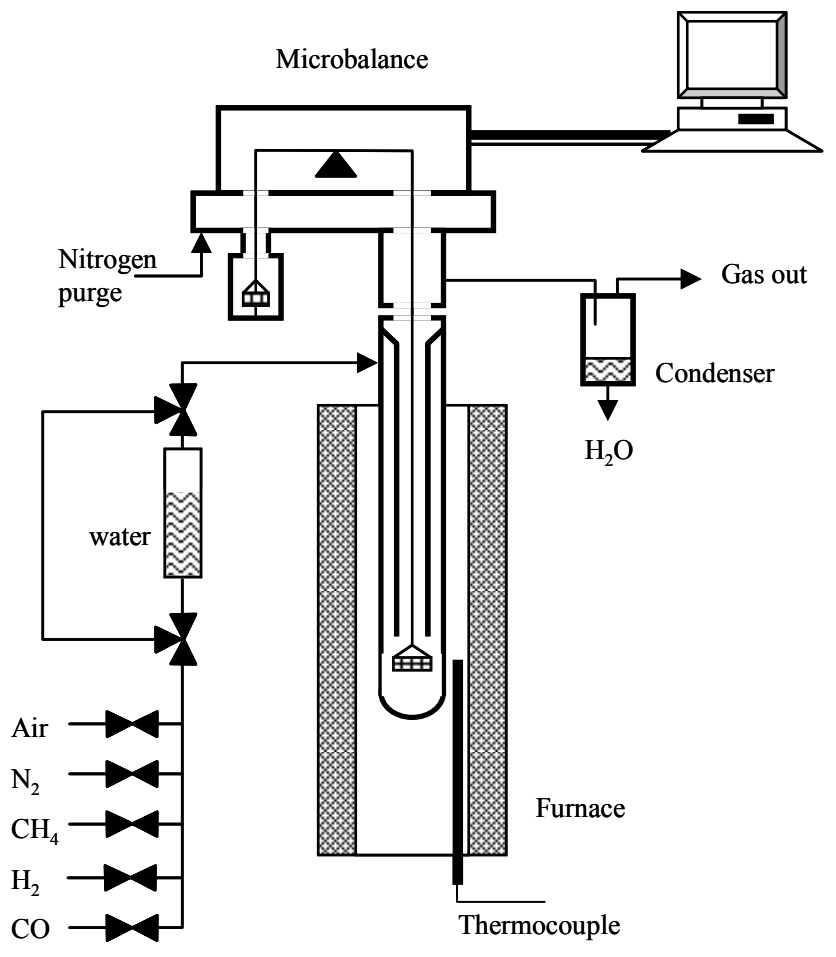

Figure 1. 
Development of Cu-based Oxygen Carriers for Chemical-Looping Combustion. Luis F. de Diego et al.

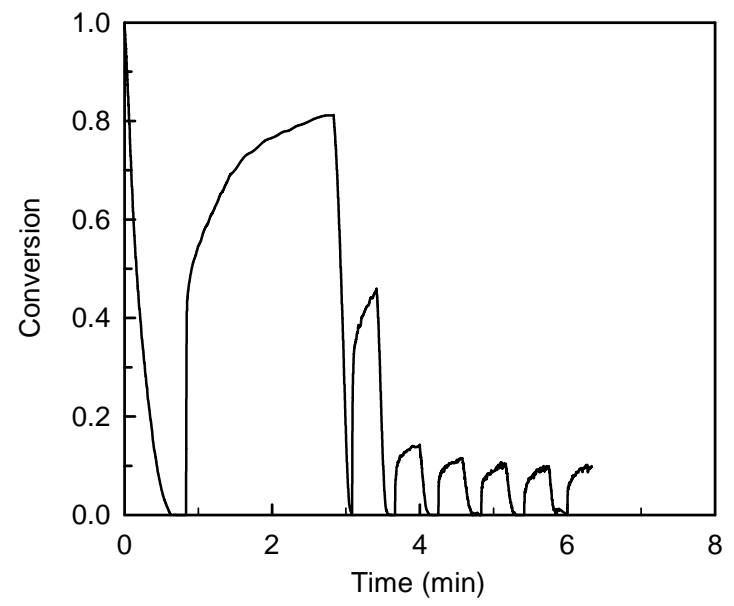

Figure 2. 
Development of Cu-based Oxygen Carriers for Chemical-Looping Combustion. Luis F. de Diego et al.
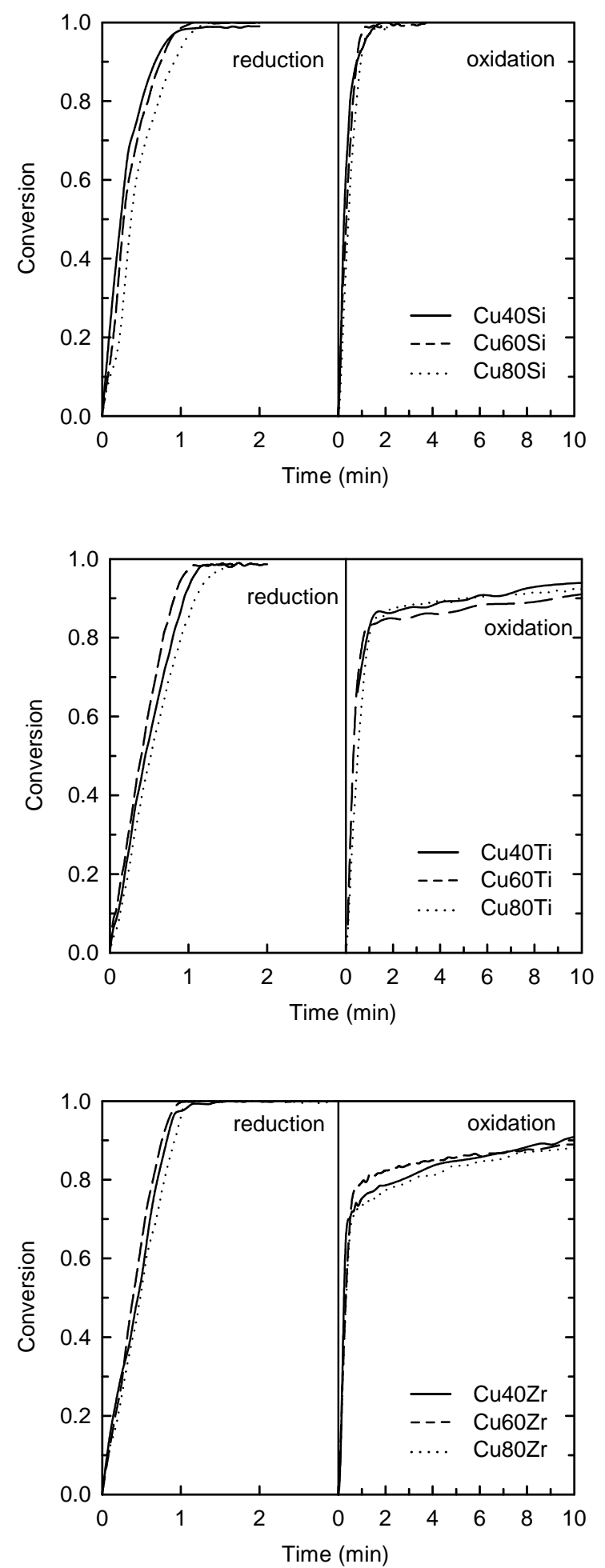

Figure 3. 
Development of Cu-based Oxygen Carriers for Chemical-Looping Combustion. Luis F. de Diego et al.

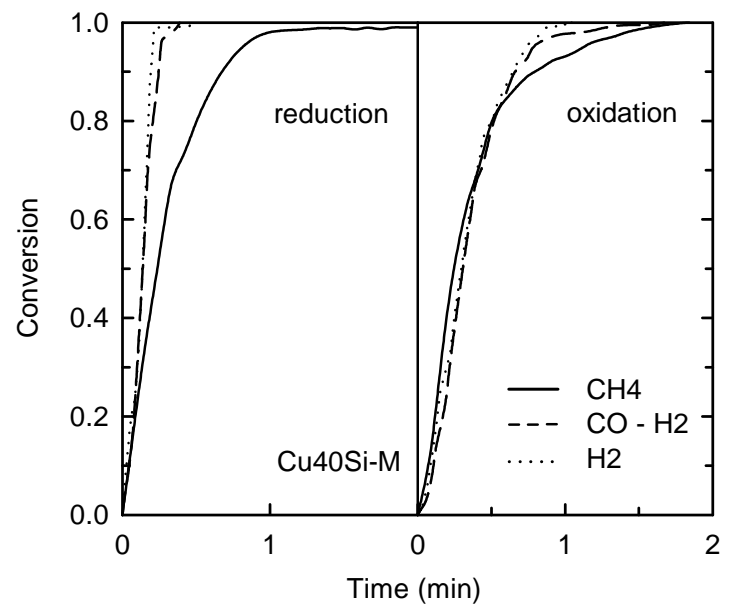

Figure 4. 
Development of Cu-based Oxygen Carriers for Chemical-Looping Combustion. Luis F. de Diego et al.

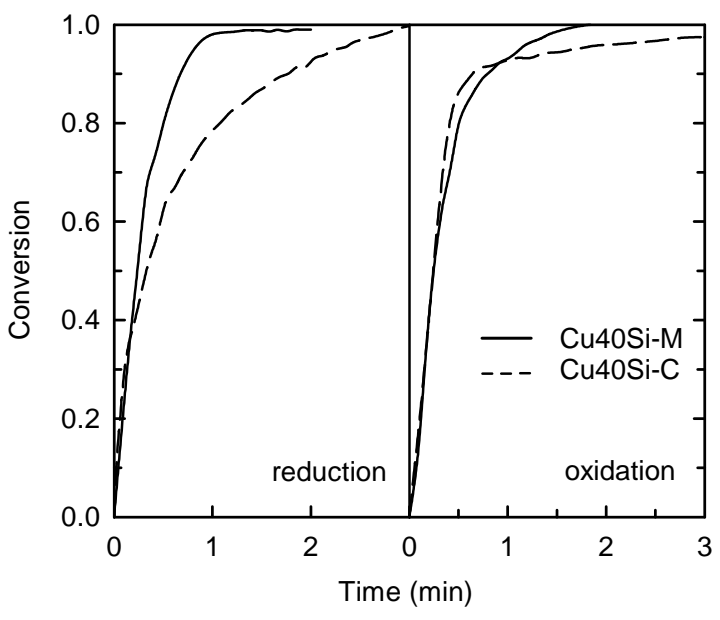

Figure 5. 
Development of Cu-based Oxygen Carriers for Chemical-Looping Combustion. Luis F. de Diego et al.

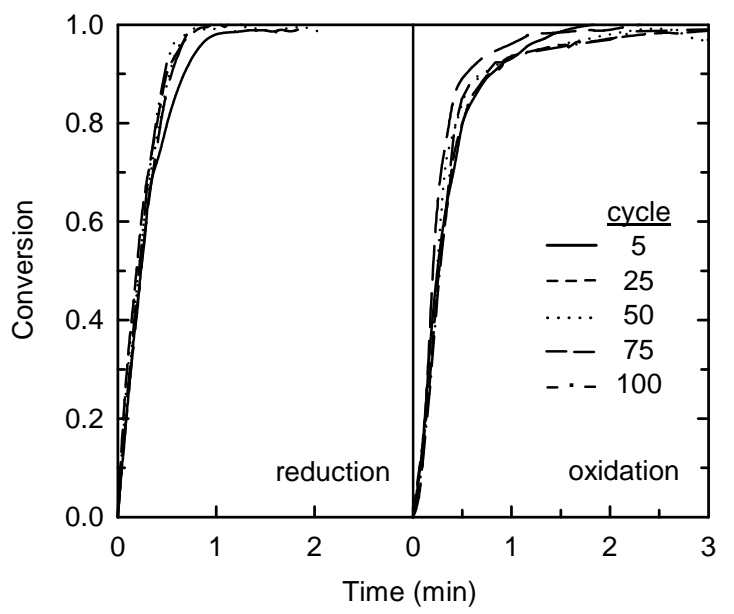

Figure 6. 
Development of Cu-based Oxygen Carriers for Chemical-Looping Combustion. Luis F. de Diego et al.

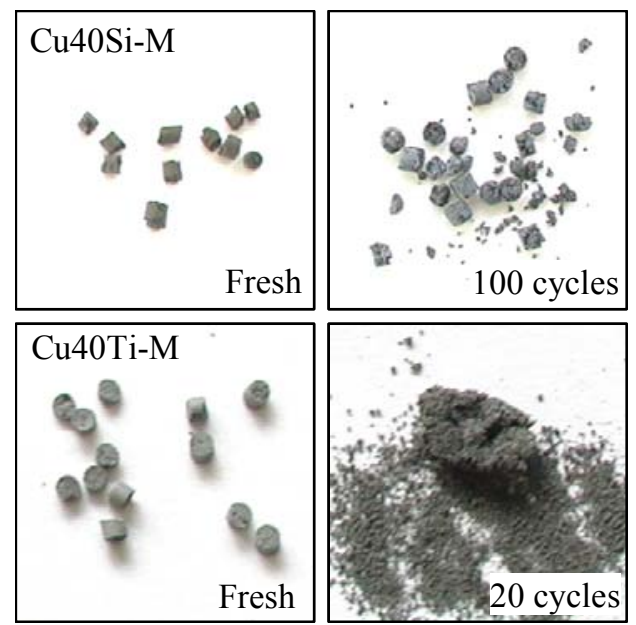

Figure 7. 
Development of $\mathrm{Cu}$-based Oxygen Carriers for Chemical-Looping Combustion. Luis F. de Diego et al.
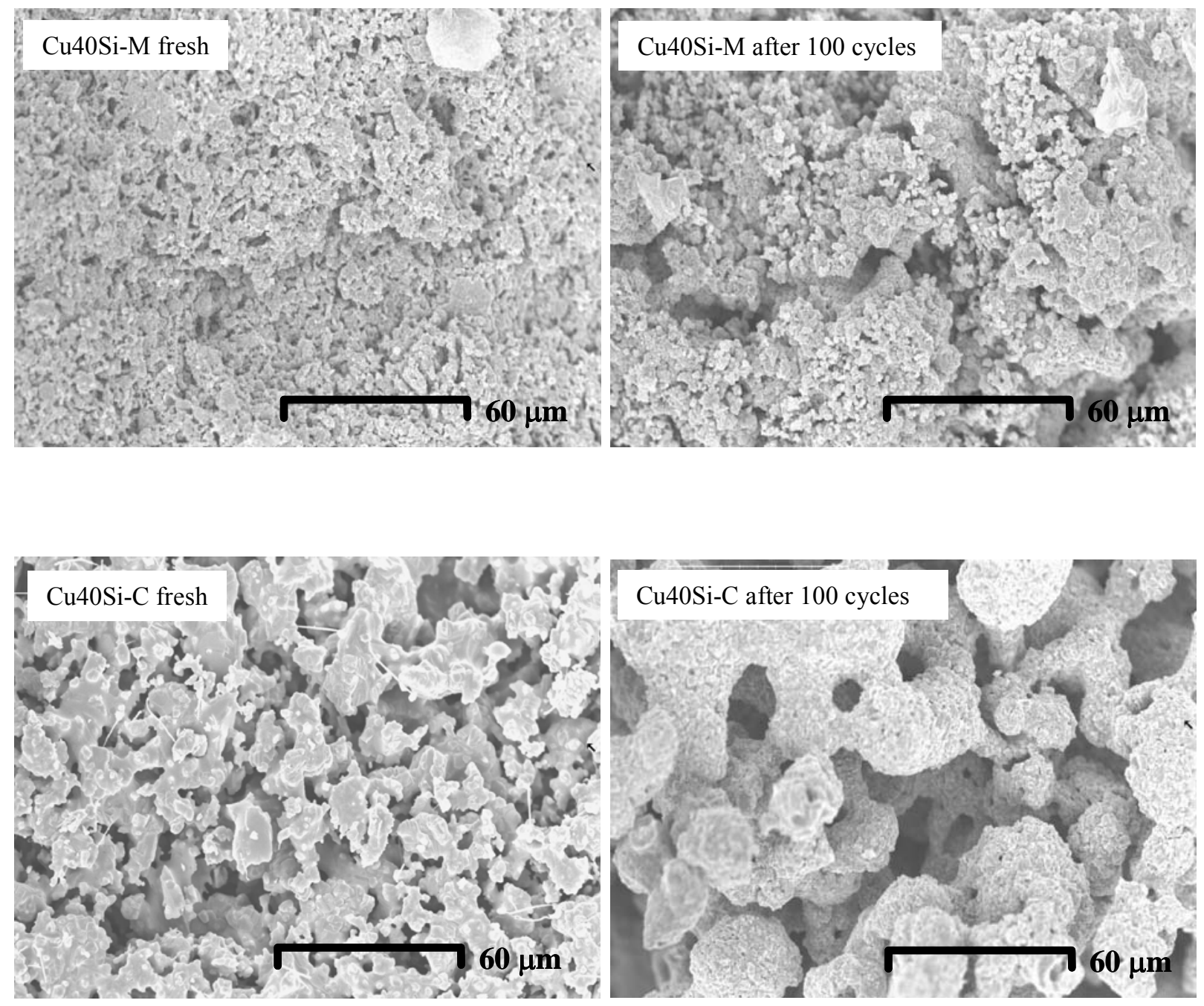

Figure 8. 
Development of Cu-based Oxygen Carriers for Chemical-Looping Combustion. Luis F. de Diego et al.
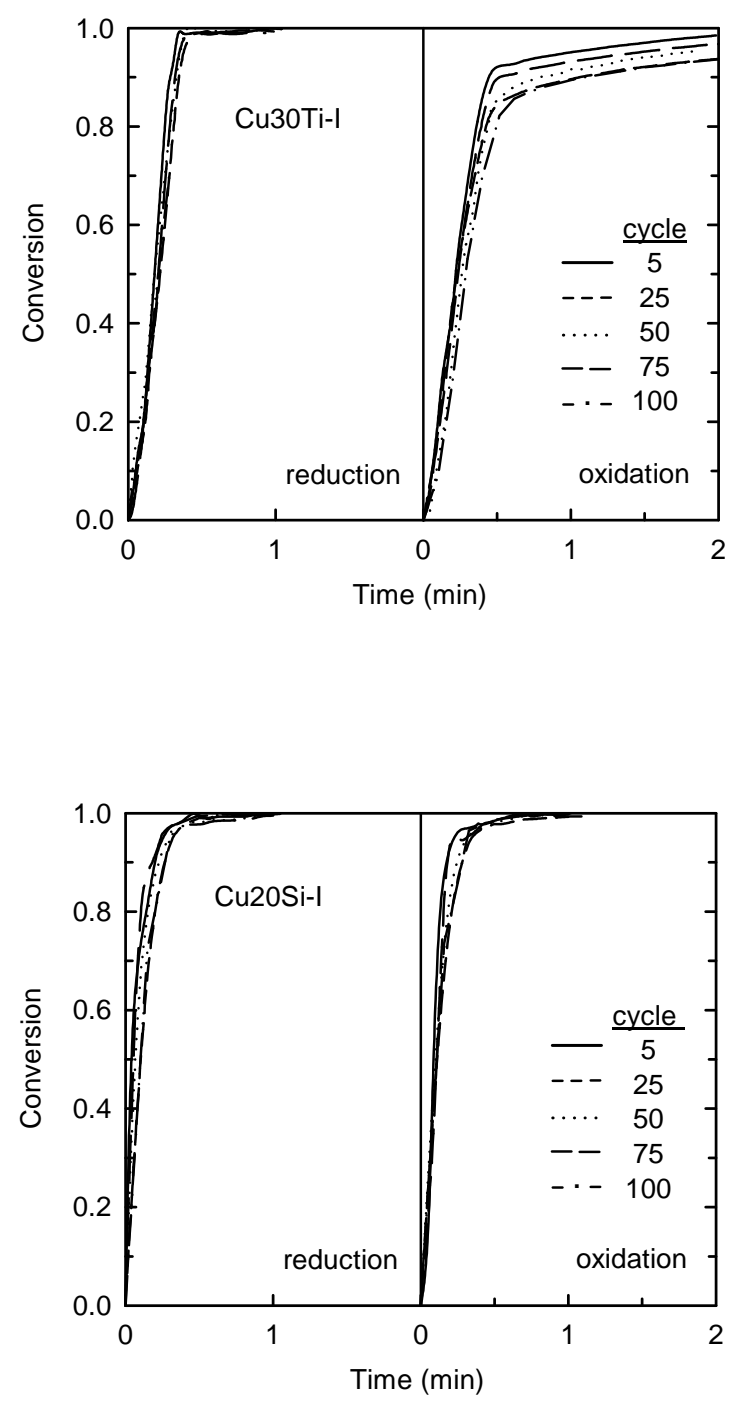

Figure 9. 
Development of Cu-based Oxygen Carriers for Chemical-Looping Combustion. Luis F. de Diego et al.
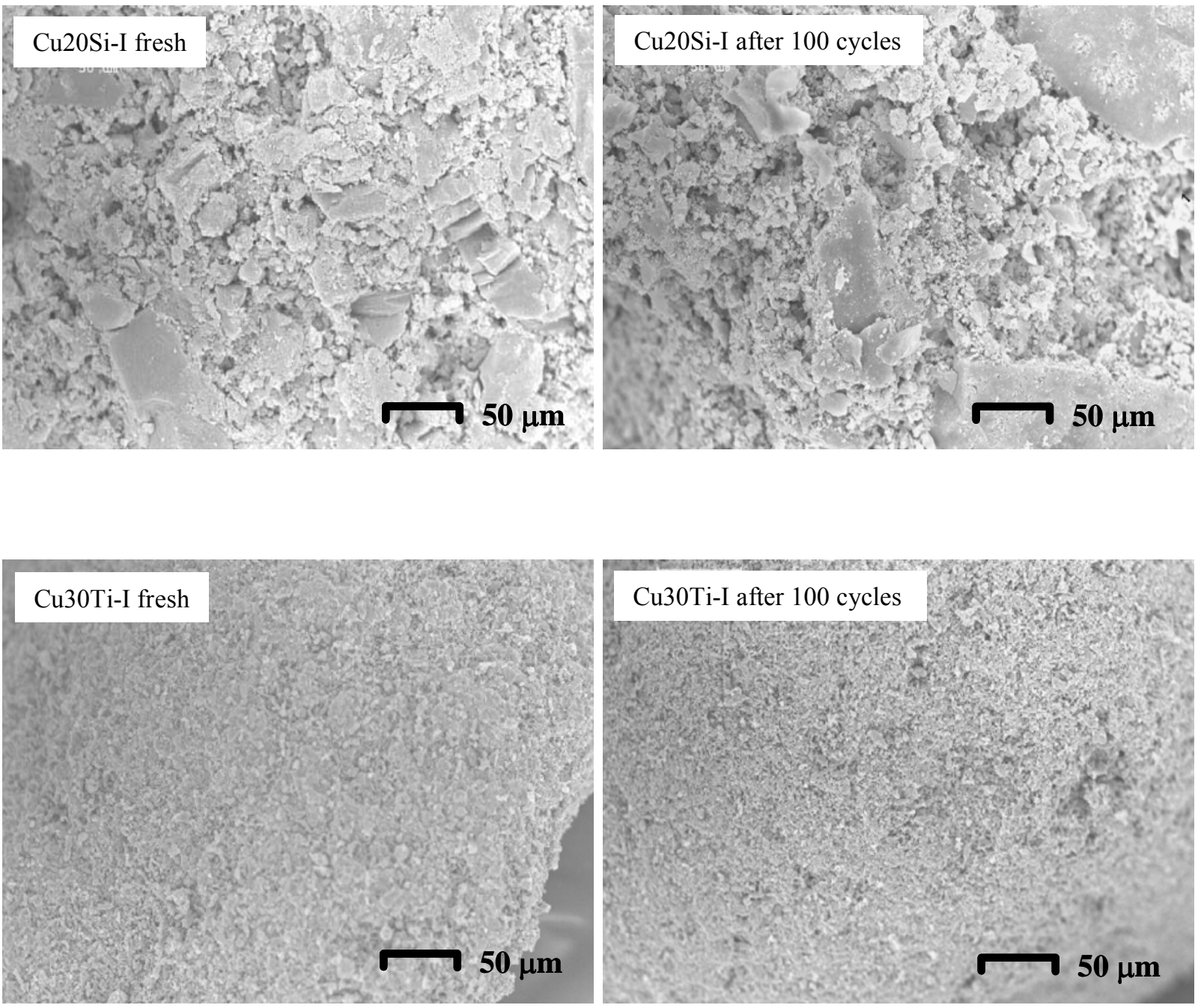

Figure 10. 